\title{
Genetic polymorphisms in patients with endometriosis: an analytical study in Goiânia (Central West of Brazil)
}

\author{
K.S.F. Silva ${ }^{1}$ and K.K.V.O. Moura ${ }^{2}$ \\ ${ }^{1}$ Laboratório de Genética e Biologia Molecular, \\ Universidade Federal de Goiás, Goiânia, GO, Brasil \\ ${ }^{2}$ Departamento de Biomedicina, \\ Pontifícia Universidade Católica de Goiás, Goiânia, GO, Brasil \\ Corresponding author: K.S.F. Silva \\ E-mail: smallbinho@hotmail.com
}

Genet. Mol. Res. 15 (2): gmr.15028135

Received November 25, 2015

Accepted April 15, 2016

Published May 25, 2016

DOI http://dx.doi.org/10.4238/gmr.15028135

\begin{abstract}
In healthy women, intra- and extracellular controls prevent the attachment and proliferation of ectopic endometrial cells. During endometriosis, abnormalities in these control mechanisms permit the survival of endometrial cells, their subsequent attachment to the peritoneal cavity, and disease progression. These abnormal cells cause invasion of tissues and induce an inflammatory response. Several genetic, immunological, and environmental factors contribute to this complex process. In this study we examined 6 polymorphisms for 6 different genes ( $p 53$; estrogen receptor $\beta$; progesterone receptor; GSTM1; GSTT1; CYP1A1). We obtained polymorphic genotype frequencies of all genes for 50 patients and analyzed them using the Fisher exact test or $\mathrm{G}$ test. Initially, we analyzed the genes in groups of 2, followed by 3 . We found a significant association between polymorphisms in 6 pairs of genes ( $p 53-E R \beta$ showed 5.9-times higher frequency in the experimental group, p53-GSTMI showed 2.39 times higher, $65.5 \%$ patients showed $p 53$-CYP1A1 polymorphism, ER $\beta$-PROGINS showed
\end{abstract}


3.0-times higher frequency, while $31.25 \%$ patients showed GSTM1PROGINS and GSTT1-CYP1A1 polymorphism). Positive results were found in 15 situations when genes were analyzed in groups of 3; the most significant result corresponded to polymorphisms of $p 53, E R \beta$ and GSTM1 seen in 20\%; PROGINS, ER $\beta$ and GSTM1 in 18\%; and $p 53, E R \beta$ and PROGINS in $12 \%$ patients. The results indicate that the presence of polymorphisms in more than one endometriosis-related gene is associated with onset of disease and progression. Future studies should focus on these genes to understand their inter-relationships and explore the possibility of developing new diagnostic techniques based on molecular markers.

Key words: $p 53$; Estrogen receptor $\beta$; Progesterone receptor; GSTM1; GSTT1; CYP1A1

\section{INTRODUCTION}

Endometriosis has been recognized as a disease condition since 1500 B.C. The symptoms described by the Egyptians at that time are the same as those observed today, including chronic pelvic pain and menstrual cycle changes (Nakata et al., 2004). Since the 1980 s, researchers realized that the products of endometrial cells and immune cells present in the peritoneal fluid could exert a toxic effect on the reproductive function. Sampson (1927) defined endometriosis as the scientific community knows it today, arguing that retrograde menstruation corresponds to the primary etiology of the disease.

Endometriosis is a complex disorder, bringing together genetic and environmental factors that contribute to determination of the disease phenotype (Tsuchiya et al., 2005). The presence of ectopic endometrial tissue is one of the most striking manifestations seen in patients with endometriosis. The disease is considered as benign and chronic depending on the release of estrogen and it is the major cause of infertility and chronic pelvic pain (Nnoaham et al., 2011). Endometriosis is a disease of modern women, more commonly seen in patients who have not reached menopause. Additionally, it is a major cause of recurrent abortion, probably caused by the presence of abnormal auto-antibodies (Nothnick, 2001). Although it exhibits benign metastatic features, the condition also shows malignant behavior such as aggressive growth and tissue invasion (Kyama et al., 2011).

Several intracellular and extracellular controls prevent implantation and proliferation of ectopic endometrial cells in healthy women. An imbalance in any of these control mechanisms allows survival of these ectopic cells, their implantation, and consequent progression of endometriosis. Endometrial cells with genetic polymorphisms may respond to local signals and then escape apoptotic processes. The products of these abnormal cells stimulate tissue invasion and induce inflammatory response (Kyama et al., 2011).

Patients with endometriosis show increased levels of substances including peritoneal fluid, immune cells such as macrophages and lymphocytes, natural killer cells, mesothelial cells, autoantibodies, cytokines, growth factors, adhesion molecules, enzymes, hormones, prostaglandins, and reactive oxygen species.

One of the first theories to explain the pathogenesis of endometriosis, the retrograde menstruation theory, supports the dissemination and ectopic implantation of endometrial 
cells and tissue fragments in the pelvic cavity (Paul Dmowski and Braun, 2004). This theory is supported by the presence of viable endometrial tissue in the peritoneal fluid and anatomical arrangement of endometrial implants. All women of reproductive age have some degree of retrograde menstruation, thus it suggests that all women also exhibit a certain degree of endometriosis (Koninckx et al., 1994). This explanation is controversial because ectopic implants do not progress in normal women, being eliminated by immune cells or apoptosis; although these processes generally occur at the end of a menstrual cycle, they are altered in patients with endometriosis. The debate then is remains, regarding the sequence of events leading to development and progression of the disease. Currently, the most plausible explanation is alteration of the immune system.

Endometriosis is a gynecological condition that affects approximately 10 to $15 \%$ women of reproductive age (Bischoff and Simpson, 2004) and about 40\% women with infertility issues. Endometriosis also affects 30 to $50 \%$ women with premenopausal symptoms (Rogers et al., 2009). These figures represent approximately 180 million women, worldwide. The risk of developing endometriosis is between 5 and $8 \%$ in first-degree relatives; it is a progressive disease in 40 to $50 \%$ of all affected women (Bischoff and Simpson, 2004). Recurrence is frequently observed after surgery or after drug therapy, especially in women with moderate to severe endometriosis (Gao et al., 2006).

Susceptibility to the disease varies across ethnic groups. The Japanese and other Asian populations, for example, show higher rates of endometriosis than Caucasians (Sangihaghpeykar and Poindexter, 1995). Contrastingly, endometriosis is rarely found among the Orthodox Jewish (Bocker et al., 1994).

New methods based on genetic markers related to endometriosis are necessary for faster and more accurate diagnosis, including identification of patients who are at high risk of developing the disease (Kyama et al., 2011).

Many studies show that there is a delay in accurate diagnosis of the disease: approximately 8 years in the United Kingdom and approximately 12 years in the United States. Detection via simple pelvic examination is a challenge (Arndt et al., 2002); laparoscopy combined with histological confirmation is the method of choice for diagnosis (Nnoaham et al., 2011). Non-invasive and promising diagnostic may be developed in the near future since women with endometriosis display different endometrial proteins expressions when to with a control group. A 2-dimensional analysis of the endometrial or peritoneal fluid using an electrophoresis gel may show differences in expression of these proteins in normal versus women with endometriosis (Casado-Vela et al., 2009). Patients with endometriosis frequently experience delayed diagnosis, resulting in considerable reduction in their quality of life and loss of work productivity, where severity of the disease and chronic pelvic pain are directly responsible (Nnoaham et al., 2011).

\section{Genes that may be related to endometriosis}

The present work analyzes polymorphisms in certain genes that may be related to the endometriosis onset and progression.

\section{Detoxification enzymes}

The enzyme glutathione-S-transferase (GST)-M1 (GSTM1) is involved in the 
detoxification of the pollutant, dioxin, which is released in the environment after combustion of organochlorine products. Enzymes of the GST family are involved in the breakdown of xenobiotic 2,3,7,8-tetrachlorodibenzo-p-dioxin. Dioxin is a carcinogen and a teratogen compound, and the GSTM1 null mutation is associated with development of cancer due to environmental exposure and a lack of the detoxification enzyme (Kyama et al., 2011). Dioxin has multiple effects on the human reproductive system, including increasing the risk of developing endometriosis.

GSTM1 e GSTT1 (Glutathione-S-Transferase Theta 1) are extremely important in the detoxification of oxidative stress products and the renewal of the ovarian epithelium. Both, GSTM1 and GSTT1 present polymorphic loci with null alleles; several studies have reported evidence of a relationship between these genes and endometriosis (Lao et al., 2016). On the other hand, other studies have found no significant relation between these polymorphism and neoplastic disease (Yang et al., 2013).

\section{Tumor suppressor genes}

Endometriosis is related to changes in any of the tumor suppressor genes. Chromosome 17 has been the focus of previous studies by virtue of breast cancer 1 (BRCA1) and tumor protein 53 (TP53 or simply p53). Fluorescence in situ hybridization (FISH) can be used to identify aneuploidy, a genetic condition normally found in patients with endometriosis (monosomy 17) (Bischoff and Simpson, 2004).

The phosphatase and tensin homolog (PTEN) gene located on chromosome 10q23 is related to several types of cancers, including ovarian and endometrial tumors that may be related to endometriosis in some cases. Loss of heterozygosity has been reported for the PTEN gene, where positive results are higher in patients with both, carcinoma and endometriosis (Bischoff and Simpson, 2004). Mutations in p53 and PTEN genes may be involved in the transformation of endometrial cells into malignant cells.

P53, a tumor suppressor gene that participates in cell cycle regulation, is involved in the inhibition of cell proliferation and progression of various types of tumors. Mutations in p53 are reported worldwide in women with endometriosis, with several reports of a positive relationship between changes in p53 and the development of endometriosis (Bischoff and Simpson, 2004).

\section{Progesterone receptor and estrogen receptor}

Progesterone receptor gene polymorphism (PROGINS) is associated with a reduced response to progesterone. The genotypes A1/A2 or A2/A2 are associated with several gynecological disorders including endometriosis (Romano et al., 2007). Some studies show evidence for the relationship between endometriosis and this form of polymorphism (Bischoff and Simpson, 2004).

The polymorphic $\mathrm{AG}$ genotype of estrogen receptor $\beta(\mathrm{ER} \beta)$ is associated with the risk of developing endometriosis (Ko et al., 2006; Camargo-Kosugi et al., 2014). Estrogen plays an important physiological role in the body, mainly related to reproductive functions, regulating the production of gonadotrophin and its release by the pituitary gland; it is also related to mood and social behavior of the individual (Martini et al., 2012). Studies on the relationship between endometriosis and ER $\beta$ have reported that $72 \%$ patients with endometriosis show the polymorphism as compared to $49 \%$ in the control group (Bischoff and Simpson, 2004). 


\section{Aryl-hydrocarbon receptor}

The aryl hydrocarbon receptor (AhR) is a transcription factor that regulates cell differentiation and induction of phase I and II drug-metabolizing enzymes. It regulates cytochrome P450 family 1 member A1 (CYP1A1) and cytochrome P450 family 1 member B1 (CYP1B1), which are representatives of phase I. These isoforms catalyze the conversion of 17-beta-estradiol, 2-hydroxy-estradiol, and 4-hydroxy-estradiol. Changes in AhR signaling may be related to risk of endometriosis onset due to the resulting changes in the expression of CYP1A1 and CYP1B1 enzymes or increased proliferation of endometrial cells (Tsuchiya et al., 2005).

Polycyclic aromatic hydrocarbons are the most common chemical species that react with the AhR. A common pollutant that has been implicated as an environmental risk factor for developing the disease is 2,3,7,8-tetrachlorodibenzo-p-dioxin. AhR shows high affinity for dioxin (Bischoff and Simpson, 2004). The genotype distribution of this polymorphism is significantly different between patients with endometriosis and normal women. Approximately $10 \%$ of the human population shows high potential inhibition by exposure to certain xenobiotics because of polymorphisms (CYP1A $1 \mathrm{~m} 1)$. These individuals are at increased risk of developing cancer or by analogy, endometriosis (Cauchi et al., 2003).

The incidence of endometriosis in the state of Goiás, Brazil, as well as worldwide, is substantial. The number of patients with chronic pelvic pain and infertility issues due to endometriosis is on the rise. Genetic research in the area is important since this disorder is of great concern to public health in the Americas and worldwide. Through this study, we hope to provide precedent to the development of more effective diagnostics and treatments for endometriosis, which would improve quality of life and maintain levels of reproductive potential in women affected by this disease. More efficient diagnoses would translate into higher efficiency of predicting risks. We analyzed the frequency of candidate polymorphisms that may increase the risk of developing endometriosis. These genes were analyzed in groups of 2 or 3 , between the experimental group with the disease and control group. Our results show that the genetic markers selected in this study are good candidates for development of novel and faster diagnostic techniques.

\section{MATERIAL AND METHODS}

\section{Ethics statement}

The present study was reviewed and approved by the Pontifical Catholic University Research Ethics Committee. All patients included in this study provided informed consent.

\section{Specimens}

We collected peripheral blood samples from 100 patients in order to perform molecular analysis of DNA for the following genes: p53, PROGINS, GSTM1, GSTT1, CYP1A1, and ER $\beta$. We divided the patients into 2 groups: 54 women with endometriosis (mean age of 32.5 years) and 46 healthy women without clinical symptoms of the disease (mean age of 37.4 years). Diagnosis was confirmed for all patients by laparoscopy performed at the Fertile Clinic, a reference center for video laparoscopy and infertility in Goiânia, Brazil. 


\section{DNA extraction and molecular analysis}

We used different protocols for DNA extraction from peripheral blood according to the target gene using GFXTM kit (Amersham Pharmacia Biotech, USA) for PROGINS and ER $\beta$ as per the manufacturer protocol. DNA integrity was confirmed after DNA extraction and polymerase chain reaction (PCR) via electrophoresis on $2 \%$ agarose gel stained with 0.5 $\mathrm{mg} / \mathrm{mL}$ ethidium bromide, visualized using a video documentation system (VDS ${ }^{\circledR}$, Amersham Biosciences, USA).

We performed PCR for PROGINS as previously described by Costa et al (2011). Amplification parameters were as follows: 5 minutes for initial denaturation at $94^{\circ} \mathrm{C} ; 35$ cycles of denaturation at $94^{\circ} \mathrm{C}$ for $1 \mathrm{~min}$, annealing at $55^{\circ} \mathrm{C}$ for $1 \mathrm{~min}$, and polymerization at $72^{\circ} \mathrm{C}$ for $1 \mathrm{~min}$, followed by a final extension at $72^{\circ} \mathrm{C}$ for $7 \mathrm{~min}$. We used the following primers sequences to amplify the region containing PROGINS polymorphism in intron $\mathrm{G}$ of the progesterone gene 5'-GGC AGA AAG CAA AAT AAA AAG A-3' (primer 5') and 5'-AAA GTA TTT TCT TGC TAA ATG TC-3' (primer 3'). The amplification resulted in 2 different PCR products; the first was designated as A1, with 149 base pairs and corresponding to the wild-type allele; while the second was designated as A2, with 455 base pairs, resulting from the insertion of 306 base pairs into intron G. We identified 3 kinds of genotypes for the patients: homozygous for the wild type (A1/A1) and homozygous (A2/A2) or heterozygous (A1/A2) for the polymorphic type (Costa et al., 2011).

We performed PCR for ER $\beta$ as previously described by Silva et al. (2011). The control contained 409 base pairs and the variants A and G contained 127 base pairs: RsaI Fw 5'-ACT TGC CAT TCT GTC TCT ACA-3', $R s a$ I Control Rev 5'-CAC AGG ACC CTG AAT CTC-3', $R s a$ I A Rev 5'-AGC TCT CCA AGA GCC GT-3', Rev G RsaI 5'-AGC TCT CCA AGA GCC GC-3'. Amplification parameters were as follows: 3 min for initial denaturation at $96^{\circ} \mathrm{C} ; 35$ cycles of denaturation at $96^{\circ} \mathrm{C}$ for $1 \mathrm{~min}$, annealing at $58^{\circ} \mathrm{C}$ for $30 \mathrm{sec}$ and polymerization at $72^{\circ} \mathrm{C}$ for $3 \mathrm{~min}$, followed by a final extension at $72^{\circ} \mathrm{C}$ for $7 \mathrm{~min}$. Genotype results for $R \mathrm{sal}$ polymorphism of the ER $\beta$ gene are AA, AG, or GG (Silva et al 2011).

DNA extraction for $\mathrm{p} 53$ analysis was performed using Illustra ${ }^{\mathrm{TM}}$ Blood Genomic DNA kit (GE HealthCare, USA). We used the following primers: Pro-72 (Fw-5'-GCC AGA GGC TGC TCC CCC-3' and Rev-5'-CGT GCA AGT CAC AGA CTT-3') and Arg-72 (Fw-5'-TCC CCC TTG CCG TCC CAA-3' and Rev-5'-CTG GTG CAG GGG CCA CGC-3'), as previously described by Ribeiro Júnior et al. (2009). For GSTM1, GSTT1, and CYP1A1m1 analyses we performed DNA extraction using Wizard $^{\mathbb{B}}$ (Genomic DNA Purification Kit). GSTM1 primers were as follows: Fw-5'-GAA CTC CCT GAA AAG CTA AAG C-3' and Rev-5'-GTT GGG CTA AAT ATA CGG TGG-3'; GSTT1 primers: Fw-5'-TTC CTT ACT GGT CCT CAC ATC TC-3' and Rev-5'-TCA CCG GAT CAT GGC CAG CA-3'; CYP1A1m1 primers: Fw5'-TAG GAG TCT TGT CTC ATG GCC T-3' and Rev-5'-CAG TGA AGA GGT GTA GCC GCT-3'. The 3 latter genes were analyzed as previously described by Silva et al. (2011). The protocol for p53, GSTM1, GSTT1, and CYP1A1m1 PCR were as that previously described for PROGINS (Costa et al., 2011; Frare et al., 2013).

\section{Statistical analysis}

We evaluated the frequencies of studied polymorphisms (p53, PROGINS, ER $\beta$, GSTM1, GSTT1, and CYP1A1m1) and comparing the experimental versus control groups as 
follows. Firstly, we analyzed frequencies for genes grouped by 2 (for example, we compared if the frequencies of p53 polymorphism and GSTM1 null polymorphism in a patient with endometriosis could be a factor to increase risk of developing endometriosis). We then compared genotype distributions between experimental and control groups using the Fisher exact test. Next, we analyzed the genes in groups of 3 and used G test (contingency analysis) to compare the frequencies between the experimental and control groups. All results are reported within $95 \%$ confidence interval (CI). A P or G value $<0.05$ was considered statistically significant. All statistical tests were performed using the Bioestat ${ }^{\circledR}$ version 5.0 software (Ayres and Ayres, 2007).

\section{RESULTS}

The prevalence of p53, PROGINS, ER $\beta$, CYP1A1, GSTM1, and GSTT1 polymorphisms, taken 2 by 2 , in women with sporadic endometriosis and endometriosis-free women is summarized in Table 1, showing frequencies of polymorphisms that resulted in $\mathrm{P}$ values of $<0.05$. Comparing the genes $\mathrm{p} 53$ and $\operatorname{ER} \beta(\mathrm{P}=0.0110), 53.12 \%$ patients with endometriosis in the experimental group showed polymorphism (Arg/Prol + Prol/Prol + AG) versus $9.00 \%$ subjects in the control group. This result suggests a relationship between the presence of polymorphic genotypes and endometriosis.

\begin{tabular}{|c|c|c|c|c|}
\hline Genes & Polymorphic genotype & $\mathrm{P}^{*}$ & $\mathrm{E}^{* *}$ & $\mathrm{C}^{* * * *}$ \\
\hline $\mathrm{p} 53$ and $\mathrm{ER} \beta$ & Arg/Prol + Prol/Prol + AG & 0.0110 & $53.12 \%$ & $9.00 \%$ \\
\hline p53 and GSTM1 & Arg/Prol + Prol/Prol + null-GSTM1 & 0.0280 & $56.25 \%$ & $23.53 \%$ \\
\hline p53 and CYP1A1 & Arg/Prol + Prol/Prol + W1m1 + m1m1 & 0.0079 & $31.25 \%$ & $0.00 \%$ \\
\hline ER $\beta$ and PROGINS & $\mathrm{AG}+\mathrm{A} 1 \mathrm{~A} 2+\mathrm{A} 2 \mathrm{~A} 2$ & 0.0227 & $65.00 \%$ & $0.00 \%$ \\
\hline PROGINS and GSTM1 & $\mathrm{A} 1 \mathrm{~A} 2+\mathrm{A} 2 \mathrm{~A} 2+$ null-GSTM1 & 0.0283 & $75.00 \%$ & $25.00 \%$ \\
\hline GSTT1 and CYP1A1 & null-GSTT1 ++ W1m1 + $\mathrm{m} 1 \mathrm{~m} 1$ & 0.0217 & $31.25 \%$ & $0.00 \%$ \\
\hline
\end{tabular}

*Fisher's exact test; **experimental group; ***control group.

When we compared the frequencies of the genes $\mathrm{p} 53$ and GSTM1, 56.25\% patients in the experimental group exhibited the polymorphic genotypes (Arg/Prol + Prol/Prol + null-GSTM1). Only $23.53 \%$ subjects presented these genotypes in the control group. This result shows a positive relationship for the presence of polymorphic genotypes and the disease $(\mathrm{P}=0.0280)$.

A comparison between the polymorphisms of p53 and CYP1A1 (Arg/Prol + Prol/ Prol $+\mathrm{W} 1 \mathrm{~m} 1+\mathrm{m} 1 \mathrm{~m} 1)$ showed that no subject in the control group presented with both polymorphisms simultaneously, while $31.25 \%$ patients in the experimental group carried the risk genotypes. This result is statistically significant $(\mathrm{P}=0.0079)$ and shows a positive relationship between the presence of the genotype with the onset of endometriosis.

No subject in the control group showed polymorphic genotypes for the genes ER $\beta$ and PROGINS $(\mathrm{AG}+\mathrm{A} 1 \mathrm{~A} 2+\mathrm{A} 2 \mathrm{~A} 2)$ versus $65.00 \%$ patients in the experimental group $(\mathrm{P}=0.0227)$.

The most significant result of analyzing gene frequencies in groups of 2 was with regard to PROGINS and GSTM1 polymorphisms (A1A2 + A2A2 + null-GSTM1). Only $25.00 \%$ subjects in the control group showed this polymorphic genotype versus $75.00 \%$ patients in the experimental group.

Analysis for GSTT1 and CYP1A1 resulted in $\mathrm{P}=0.0217$, indicating a relationship between the presence of polymorphism and endometriosis development. In this case, $31.25 \%$ 
patients in the experimental group presented at-risk genotypes simultaneously, versus none in the control group.

Table 2 summarizes the results of genotypes exerting a protective effect against endometriosis onset and progression. Comparing the genes p53 and ER $\beta$, we observed that $27.80 \%$ subjects in the control group showed genotypes Arg/Arg + AA + GG versus $87.50 \%$ patients in the experimental group. Due to the statistically significant difference $(\mathrm{P}=0.0074)$, a lower rate of these genotypes in healthy subjects is indicative of protection against the development of endometriosis.

Table 2. Genotypes with protective effect against endometriosis in the experimental and control groups.

\begin{tabular}{l|l|c|c|c}
\hline Genes & Polymorphic genotype & P* & $\mathrm{E}^{* *}$ & $\mathrm{C}^{* * *}$ \\
\hline $\mathrm{p} 53$ and ER $\beta$ & $\mathrm{Arg} / \mathrm{Arg}+\mathrm{AA}+\mathrm{GG}$ & 0.0074 & $87.50 \%$ & $27.80 \%$ \\
\hline $\mathrm{p} 53$ and PROGINS & $\mathrm{Arg} / \mathrm{Arg}+\mathrm{A} 1 \mathrm{~A} 1$ & 0.0431 & $59.38 \%$ & $35.30 \%$ \\
\hline $\mathrm{p} 53$ and CYP1A1 & $\mathrm{Arg} / \mathrm{Arg}+\mathrm{W} 1 \mathrm{~W} 1$ & 0.0302 & $100.00 \%$ & $77.78 \%$ \\
\hline $\mathrm{ER} \beta$ and PROGINS & $\mathrm{AA}+\mathrm{GG}+\mathrm{A} 1 \mathrm{~A} 1$ & 0.0009 & $88.89 \%$ & $41.18 \%$ \\
\hline $\mathrm{ER} \beta$ and GSTM1 & $\mathrm{AA}+\mathrm{GG}+\mathrm{GSTM} 1$ & 0.0009 & $92.86 \%$ & $38.46 \%$ \\
\hline $\mathrm{ER} \beta$ and GSTT1 & $\mathrm{AA}+\mathrm{GG}+\mathrm{GSTT} 1$ & 0.0003 & $100.00 \%$ & $40.00 \%$ \\
\hline ER $\beta$ and CYP1A1 & $\mathrm{AA}+\mathrm{GG}+\mathrm{W} 1 \mathrm{~W} 1$ & 0.0302 & $100.00 \%$ & $73.68 \%$ \\
\hline GSTM1 and CYP1A1 & GSTM1 + W1W1 & 0.0008 & $100.00 \%$ & $69.23 \%$ \\
\hline GSTT1 and CYP1A1 & GSTT1 + W1W1 & 0.0095 & $100.00 \%$ & $76.47 \%$ \\
\hline
\end{tabular}

*Fisher's exact test; **endometriosis group; ***control group.

The genotypes Arg/Arg + A1A1 related to the genes p53 and PROGINS that play an important role, exerting a protective effect against the disease $(\mathrm{P}=0.0431)$. In the control group, $35.30 \%$ subjects carried the genotypes with the protective effect against of $59.38 \%$ patients in the endometriosis group.

Regarding the homozygous genotypes Arg/Arg + W1W1 corresponding to the genes p53 e CYP1A1, 77.78\% subjects in the control group showed these specific genotypes against $100.00 \%$ patients in the experimental group $(\mathrm{P}=0.0302)$.

When we compared the genotypes AA + GG + A1A1, related to the genes ER $\beta$ and PROGINS, we found a positive result for protective effect against the onset of the disease ( $\mathrm{P}$ $=0.0009) ; 88.89 \%$ of the patients in the experimental group had these protective genotypes against $41.18 \%$ subjects in the control group.

ER $\beta$ and GSTM1 (GSTM1 + AA + GG) also play a protective role against the development of endometriosis. In the control group, $38.46 \%$ subjects carried the protective genotype against $92.86 \%$ patients in the experimental group. This result is statistically significant due to the high difference in the frequencies of these genotypes for the two groups $(\mathrm{P}=0.0009)$.

ER $\beta$ and GSTT1 $(A A+G G+$ GSTT1) have a protective effect against endometriosis as well. In the experimental group all of the patients carried both genes versus $40.00 \%$ subjects in the control group; this result is statistically significant $(\mathrm{P}=0.0003)$.

All patients in the experimental group carried the genotypes AA $+\mathrm{GG}+\mathrm{W} 1 \mathrm{~W} 1(\mathrm{ER} \beta$ e CYP1A1, respectively); $73.68 \%$ of the subjects in the control group also exhibited these genotypes. The result is statistically significant $(\mathrm{P}=0.0302)$.

Regarding the genotypes GSTM1 + W1W1, related to the genes CYP1A1 and GSTM1, all patients in the experimental group and $69.23 \%$ subjects in the control group carried these protective genotypes against the disease. Thus, these genes confer a protection against the onset of this gynecological disorder $(\mathrm{P}=0.0008)$. 
The GSTT1 and CYP1A1 together also play a protective effect against endometriosis $(\mathrm{P}=0.0095)$. All patients in the experimental group carried the homozygous genotype for both genes (GSTT1 + W1W1), against $76.47 \%$ of the subjects in the control group.

The frequencies of the polymorphic genes analyzed 3 by 3 in the control group and in the experimental group patients are summarized in Tables 3 and 4. A comparison between polymorphisms of p53, ER $\beta$, and PROGINS (Arg/Prol + Prol/Prol + AG + A1A2 + A2A2) showed a statistically significant result with $\mathrm{G}=0.0118$. No subject in the control group showed those 3 polymorphisms simultaneously, while $12.00 \%$ of the patients in the experimental group showed simultaneous polymorphisms. The results suggest that these genotypes contribute to onset of the disease.

\begin{tabular}{|c|c|c|c|c|}
\hline Genes & Polymorphic genotype & $\mathrm{G}^{*}$ & $E^{* *}$ & $\mathrm{C}^{* * *}$ \\
\hline $\mathrm{p} 53, \mathrm{ER} \beta$ and PROGINS & Arg/Prol + Prol/Prol + AG + A1 A2 + A2A2 & 0.0118 & $12.00 \%$ & $0.00 \%$ \\
\hline p53, CYP1A1 and PROGINS & Arg/Prol/Prol/Prol + W1m1/m1m1 + A1A2/A2A2 & 0.0035 & $04.00 \%$ & $0.00 \%$ \\
\hline PROGINS, ER $\beta$ and GSTM1 & $\mathrm{A} 1 \mathrm{~A} 2+\mathrm{A} 2 \mathrm{~A} 2+\mathrm{AG}+$ null-GSTM1 & 0.0067 & $18.00 \%$ & $0.00 \%$ \\
\hline PROGINS, ER $\beta$ and GSTT1 & $\mathrm{A} 1 \mathrm{~A} 2+\mathrm{A} 2 \mathrm{~A} 2+\mathrm{AG}+$ null-GSTT1 & 0.0062 & $10.00 \%$ & $0.00 \%$ \\
\hline PROGINS, ER $\beta$ and CYP1A1 & $\mathrm{A} 1 \mathrm{~A} 2+\mathrm{A} 2 \mathrm{~A} 2+\mathrm{AG}+\mathrm{W} 1 \mathrm{~m} 1 / \mathrm{m} 1 \mathrm{~m} 1$ & 0.0166 & $04.00 \%$ & $0.00 \%$ \\
\hline $\mathrm{p} 53, \mathrm{ER} \beta$ and GSTM1 & Arg/Prol + Prol/Prol + AG + null-GSTM1 & 0.0039 & $20.00 \%$ & $0.00 \%$ \\
\hline p53, ER $\beta$ and GSTT1 & Arg/Prol + Prol/Prol + AG + null-GSTT1 & 0.0070 & $14.00 \%$ & $05.26 \%$ \\
\hline
\end{tabular}

${ }^{*} \mathrm{G}$ test; $* *$ experimental group; $* * *$ control group.

Table 4. Polymorphic genotypes analyzed in groups of 3 in the experimental and control groups.

\begin{tabular}{|c|c|c|c|c|}
\hline Genes & Polymorphic genotype & $\mathrm{G}^{*}$ & $\mathrm{E}^{* *}$ & $\mathrm{C}^{* * *}$ \\
\hline p53, GSTM1 and GSTT1 & Arg/Prol + Prol/Prol + null-GSTM1 + null-GSTT1 & 0.0192 & $10.00 \%$ & $02.50 \%$ \\
\hline p53, GSTM1 and CYP1A1 & Arg/Prol/Prol/Prol + null-GSTM1 + W1m1/mlml & 0.0008 & $08.00 \%$ & $0.00 \%$ \\
\hline p53, GSTT1 and CYP1A1 & Arg/Prol/Prol/Prol + null-GSTT1 + W1m1/m1ml & 0.0059 & $10.00 \%$ & $0.00 \%$ \\
\hline PROGINS, GSTT1 and CYP1A1 & $\mathrm{A} 1 \mathrm{~A} 2+\mathrm{A} 2 \mathrm{~A} 2+$ null-GSTT1 + W1 $1 \mathrm{~m} / \mathrm{m} 1 \mathrm{~m} 1$ & 0.0029 & $02.00 \%$ & $0.00 \%$ \\
\hline ER $\beta$, GSTM1 and GSTT1 & AG + null-GSTM1 + null-GSTT1 & 0.0042 & $10.00 \%$ & $05.26 \%$ \\
\hline ER $\beta$, GSTT1 and CYP1A1 & $\mathrm{AG}+$ null-GSTT1 $+\mathrm{W} 1 \mathrm{~m} 1 / \mathrm{m} 1 \mathrm{~m} 1$ & 0.0007 & $04.00 \%$ & $0.00 \%$ \\
\hline CYP1A1, GSTM1 and GSTT1 & W1 $1 \mathrm{~m} 1 / \mathrm{m} 1 \mathrm{~m} 1+$ null-GSTM1 + null-GSTT1 & 0.0011 & $02.00 \%$ & $05.26 \%$ \\
\hline ER $\beta$, GSTM1 and CYP1A1 & $\mathrm{AG}+$ null-GSTM $1+\mathrm{W} 1 \mathrm{~m} 1 / \mathrm{m} 1 \mathrm{~m} 1$ & 0.0014 & $04.00 \%$ & $0.00 \%$ \\
\hline
\end{tabular}

${ }^{*} \mathrm{G}$ test; ** experimental group; ***control group.

We obtained a significant result $(\mathrm{G}=0.0035)$ for $\mathrm{p} 53$, CYP1A1, and PROGINS (Arg/ Prol + Prol/Prol $+\mathrm{W} 1 \mathrm{~m} 1+\mathrm{m} 1 \mathrm{~m} 1+\mathrm{A} 1 \mathrm{~A} 2+\mathrm{A} 2 \mathrm{~A} 2)$, indicating a relationship between the disease and simultaneous presence of these 3 genotypes in patients with endometriosis. No patient in the control group showed those 3 polymorphic genotypes simultaneously, versus $04.00 \%$ patients in the experimental group.

PROGINS, ER $\beta$ and GSTM1 (A1A2 + A2A2 + AG + null-GSTM1) also exhibited a significant relationship with endometriosis onset $(G=0.0067)$. No subject in the control group showed the 3 genotypes simultaneously, versus $18.00 \%$ patients in the experimental group.

When we compared the genes PROGINS, ER $\beta$ and GSTT1 for the presence of polymorphisms (A1A2 + A2A2 + AG + null-GSTT1) we found a statistically significant result $(\mathrm{G}=0.0062)$; no subject in the control group showed these genotypes versus $10.00 \%$ patients in the experimental group.

The polymorphisms A1A2 + A2A2 + AG + W1m1/m1m1 (PROGINS, ER $\beta$, and CYP1A1, respectively) showed significant results $(G=0.0166)$ when analyzed. In this case, $04.00 \%$ patients in the experimental group showed all polymorphic genotypes simultaneously versus none in the control group. 
Additionally, p53, ER $\beta$ and GSTM1 (Arg/Prol + Prol/Prol + AG + null-GSTM1) polymorphisms showed a significant result $(\mathrm{G}=0.0039) ; 20.00 \%$ patients in the experimental group carried the 3 polymorphisms simultaneously, versus none in the control group.

Polymorphisms of p53, ER $\beta$ and GSTT1 (Arg/Prol + Prol/Prol + AG + null-GSTT1) also exhibited a significant result $(\mathrm{G}=0.0070) ; 14.00 \%$ patients in the experimental group showed all 3 polymorphisms simultaneously versus $05.26 \%$ in the control group.

Frequency comparison for polymorphisms of p53, GSTM1, and GSTT1 (Arg/Prol + Prol/Prol + null-GSTM1 + null-GSTT1) showed a significant result with $G=0.0192$. While only $02.50 \%$ subjects in the control group carried these 3 polymorphisms simultaneously, $10.00 \%$ patients in the experimental group showed all of them. The result suggests that these genotypes influence the development of the disease.

We also found a statistically significant result $(\mathrm{G}=0.0008)$ for $\mathrm{p} 53$, GSTM1, and CYP1A1 (Arg/Prol + Prol/Prol + null-GSTM1 + W1 1 1 $\mathrm{m} 1 \mathrm{~m} 1)$, which indicates a relationship between the disease and the simultaneous presence of these genotypes in endometriosis patients. No patient in the control group showed these 3 genotypes simultaneously versus $08.00 \%$ patients in the experimental group.

Regarding the genes p53, GSTT1 and CYP1A1 (Arg/Prol + Prol/Prol + null-GSTT1 + $\mathrm{W} 1 \mathrm{~m} 1+\mathrm{m} 1 \mathrm{~m} 1)$, we found a significant relationship between the presence of polymorphisms and the occurrence of endometriosis $(\mathrm{G}=0.0059)$. No patient in the control group showed all the 3 genotypes simultaneously, versus $10.00 \%$ patients in the experimental group.

When we compared the polymorphisms of PROGINS, GSTT1 and CYP1A1 (A1A2 $+\mathrm{A} 2 \mathrm{~A} 2+$ null-GSTT1 $+\mathrm{W} 1 \mathrm{~m} 1+\mathrm{m} 1 \mathrm{~m} 1$ ) we found a positive, statistically significant result $(\mathrm{G}=0.0029)$; no patient in the control group showed these genotypes simultaneously, versus $02.00 \%$ patients in the experimental group.

We found significant results $(\mathrm{G}=0.0042)$ for ER $\beta$, GSTM1 e GSTT1 $(\mathrm{AG}+$ nullGSTM1 + null-GSTT1) as well; $10.00 \%$ patients in the endometriosis group showed all the polymorphic genotypes simultaneously, versus $05.26 \%$ subjects in the control group.

Polymorphisms of ER $\beta$, GSTT1, and CYP1A1 (Arg/Prol + Prol/Prol + null-GSTM1 + $\mathrm{W} 1 \mathrm{~m} 1+\mathrm{m} 1 \mathrm{~m} 1)$ showed a significant result $(\mathrm{G}=0.0007) ; 04.00 \%$ patients in the experimental group showed the 3 polymorphisms simultaneously versus none in the control group.

Polymorphisms of CYP1A1, GSTM1, and GSTT1 (W1m1 + m1m1 + null-GSTM1 + null-GSTT1-nulo) also exhibited significant results $(\mathrm{G}=0.0011) ; 02.00 \%$ of the patients in the experimental group showed these 3 polymorphisms simultaneously.

A comparison between the polymorphisms of ER $\beta$, CYP1A1 and GSTM1 (AG + null-GSTM1 $+\mathrm{W} 1 \mathrm{~m} 1+\mathrm{m} 1 \mathrm{~m} 1$ ) showed a significant result with $\mathrm{G}=0.0014$. While no subject in the control group presented all the 3 polymorphisms simultaneously, $04.00 \%$ patients in the experimental group showed all 3 simultaneously. The result suggests that these genotypes influence the onset of endometriosis.

\section{DISCUSSION}

Most scientific studies on genetic polymorphisms that may be associated with endometriosis are based on analyses of individual genes; they compare the frequency of the polymorphisms between the experimental and control group. Our results are consistent with those reported by Silva et al. (2011), who compared the association of p53 and ER $\beta$ polymorphisms between endometriosis patients and a control group. They found a positive 
association and a P-value lower than 0.0001 . In our study we found a statistically significant association between the 2 polymorphisms, with $\mathrm{P}=0.0110$ (Table 1).

A group from Japan (Maeda et al., 2002) showed positive results analyzing these genes and their relation to endometrial cancer, a gynecological dysfunction that may also be related to endometriosis. Their results showed that $26 \%(17 / 64)$ patients with endometrial cancer showed some alteration in the gene ER $\beta$ and p53 abnormalities were found mainly in Stage III cancer with a frequency of $88.9 \%(8 / 9)$. These results are important for the understanding of endometriosis once it is considered as a neoplastic disease.

Costa et al. (2011) studied the polymorphisms of the genes PROGINS and p53 but found no positive relationship between endometriosis and control groups $(\mathrm{P}=0.4379)$. This result is consistent with our findings since for those polymorphic genotypes we did not find a statistically significant association.

Baranova et al. (1997) found that 86\% (43/50) patients in the endometriosis group had null-GSTM1 versus $45.8 \%$ subjects in the control group. Hadfield et al. (2001) and Baxter et al. (2001) have not confirmed the significant results by Baranova et al.; however, they reported polymorphisms for 45 and $48 \%$ patients in the experimental group with null-GSTM1, respectively. Our group found $56.25 \%$ women with endometriosis carried these polymorphisms.

An interesting study in Korea (Ko et al., 2006) is related to polymorphism of ER $\beta$ PROGINS. The survey consisted of 100 women with endometriosis confirmed by surgery and a control group of 110 healthy women. The group used the $\mathrm{c}^{2}$ test to compare genotype distribution and they found values of $\mathrm{P}<0.05$, suggesting that the polymorphisms are associated with an increased risk of developing endometriosis in the Korean population. This result is compatible with our results; we found a positive association between the polymorphisms ER $\beta$ and PROGINS between endometriosis and control group, $\mathrm{P}=0.0227$ (Table 1).

Some authors suggest the relation between 533 and CYP1A1 to the development of lung cancer (Kawajiri et al., 1993). The authors found a statistically significant result between p53 and CYP1A1 with the increased risk of lung cancer in smokers; they also realized that p53 alterations alone would be able to increase the risk of developing this type of cancer (Kawajiri et al., 1993). We found statistically significant P-value of 0.0079 (Table 1). We also found an association of CYP1A1 and p53 $(\mathrm{P}=0.0302)$ regarding protection against endometriosis development.

A group from the United States (Ricci et al., 1999) conducted studies with endometrial cells. They realized that changes in the gene ER $\beta$ (or its expression) lead to a significant reduction in the activity of metabolizing enzymes such as CYP1A1. These findings support the idea that those 2 genes may be involved in the development of endometriosis. We found a positive relation $(\mathrm{P}=0.0302$ showed on Table 2$)$ between the homozygous genotype (AA + GG + W1W1) and the protective effect that they may have against the development of the disease.

In the present study, we found a significant positive correlation $(\mathrm{P}=0.0008$ on table 2$)$ when we compared the genes GSTM1 and CYP1A1. Two major studies (Hadfield et al., 2001; Arvanitis et al., 2003) showed an association between polymorphisms of these genes; these groups stated concluded that the wild genotypes might exert a protective effect against the onset and development of endometriosis. However, another survey in Greece (Arvanitis et al., 2001) using the same genes found a result different from ours. They compared a group of 275 women with endometriosis to a group of 346 fertile women without endometriosis. According to their results, the genotypes $\mathrm{W} 1 / \mathrm{m} 1+\mathrm{m} 1 \mathrm{~m} 1$ combined with null-GSTM1 increase the risk of the disease development and progression. The outcome of our work shows that these 2 polymorphisms are not associated with endometriosis; P-value is higher than 0.05 . 
We found a positive correlation ( $\mathrm{P}=0.0217)$ when we compared GSTT1 and CYP1A1 polymorphisms; our result is not consistent with a study conducted in India (Babu et al., 2005), which found no relationship between the polymorphisms of GSTT1 and CYP1A1; on the other hand, they found a relationship between CYP1A1 and GSTM1 polymorphisms. The authors themselves suggest that the discrepancy among different publications around the world is due to either ethnic diversity or errors in sampling procedures.

Most analyzes comparing the frequencies of 3 genes at the same time, resulted in a significant P-value, suggesting that each polymorphism added a certain risk factor for the onset of the disease. Arvanitis et al. (2001) analyzed the genes CYP1A1, GSTM1, and GSTT1 and concluded that the mutant allele CYP1A1m1 is at a frequency significantly higher in the experimental group than in the control group (20.20 vs 14.30\%, respectively) and along with the genotype null-GSTM1 and null-GSTT1 seems to have a moderate effect the risk of developing endometriosis. This result supports our findings (Table 4), but contradicts a previous study from the same group, which concluded that the null-GSTT1 genotype alone or combined with GSTM1 or CYP1A1m1 do not add any risk to the disease (Hadfield et al., 2001).

UK researchers genotyped 148 women with endometriosis and they included 53 women in the control group; the results are compatible to the present research since they concluded that the null-GSTM1 and null-GSTT1 polymorphisms had no significant differences when comparing experimental and control group. However, if CYP1A1m1 genotypes are included in the analysis then it shows that these polymorphisms together are statistically associated with a small increase in the risk of developing the disease (Hadfield et al., 2001).

The results of a study published in the Asian Journal of Andrology (Quiñones et al., 2006) suggested that a combination of genetic polymorphisms in the genes p53, CYP1A1, and GSTM1 is related to the onset of lung cancer in smokers and prostate cancer. We found a positive result $(\mathrm{G}=0.0008)$ that corroborates the presence of those polymorphisms and the endometriosis onset (Table 4), proving the relationship between these genes and neoplastic disease. A study group in Taiwan (Wang et al., 1999), working with the same genes in lung cancer patients, found no significant relationship between the control and experimental groups. The explanation for the differences refers to sample size or ethnicity of the groups studied, not to mention the environmental factors that influence the phenotype of individuals.

A study conducted in São Paulo (Bonfitto and de Angelo Andrade, 2003) on endometrial carcinoma examined the possible relationship between polymorphisms of the genes p53, PROGINS, and ER $\beta$. The study compared the development degree of neoplasia with expression of p53, estrogen receptor, and progesterone receptor. The result showed that $\mathrm{p} 53$ alterations were present in all stages of the disease, whereas ER $\beta$ and PROGINS alterations were present only in some stages. These results (the study in Sao Paulo and the present study) indicate that abnormalities in these genes are related to endometrial changes (Bonfitto and de Angelo Andrade, 2003).

Studies conducted in Mexico (Soto-Quintana et al., 2011) on breast cancer analyzed the activity of GSTs (GSTM1 and GSTT1), estrogen and progesterone receptors. The group explored an association between null-GSTM1 and GSTT1 polymorphisms and a response to chemotherapy treatments and ER $\beta$ and PROGINS expression. The group found no statistically significant differences. Comparing these genes in groups of 3, when PROGINS, GSTM1 and GSTT1 or null-GSTM1, null-GSTT1, and PROGINS are analyzed together, we found no significant differences between control and experimental groups $(G>0.05)$. For all the other two possibilities we found significant differences; $G=0.0067$ for the frequencies of null- 
GSTM1, ER $\beta$ and PROGINS polymorphisms (Table 3); $\mathrm{G}=0.062$ for null-GSTT1, ER $\beta$ and PROGINS (Table 3). A group of researchers in the United States (Ricci et al., 1999) developed an assay to analyze the effects of estrogen and progesterone on the expression of CYP1A1. The aim of this study was to analyze the effects of the products of these genes in the metabolism of dioxin, exogenous substance known to influence the development of endometriosis. Their results show that alteration in ER $\beta$ and PROGINS lead to significant changes in the expression of CYP1A1 and therefore changes in dioxin metabolism, which in turn may influence the risk of endometriosis onset (Ricci et al., 1999). Our study found a positive relationship between the frequency of these genes polymorphisms, consistent with the results found by the American group $(\mathrm{G}=0.0166$ shown in Table 3$)$. These data enhance that knowing the roles these genes have in xenobiotic metabolism is essential for a better understanding of complex endometrial diseases (such as endometriosis).

A survey in Campinas (Ortega et al., 2007) analyzed the genes p53 and GSTs in 106 patients with myeloma and 230 controls. The results suggest no positive correlation, but the authors realized that the polymorphism of $\mathrm{p} 53$ at the codon 72 combined with null-GSTM1 polymorphism increases the disease progression. In our study we found a significant difference for these 3 genes (null-GSTM1, null-GSTM1 and p53) with G $=0.0192$ (Table 4).

Studies on breast cancer reveal a relationship between GSTM1, ER $\beta$, and p53 (Arndt et al., 2002). The results of this study show that GSTM1 gene polymorphism alone does not play a key role in the development of neoplasia; however, other polymorphisms such as p53 and ER $\beta$ have an additive effect in the onset of the disease. Their result is consistent with our results, where we found a significant difference between the frequencies of the genotypes when comparing the control and experimental groups, $\mathrm{G}=0.0039$ (Table 3).

Our most significant result refers to the polymorphisms (Arg/Prol + Prol/Prol) $+(\mathrm{GA})$ + (null-GSTM1) where the frequency of patients with that genotype was $20 \%(10 / 50)$, as shown in Table 3. This indicates that when the polymorphisms of the genes p53, GSTM1, and ER $\beta$ are present, there is a significant increase in the risk of onset and progression of endometriosis $(\mathrm{G}=0.0039)$.

\section{CONCLUSION}

The results of this study show that polymorphic genotype frequencies in the experimental group were higher than that in the control group. Rarely a patient in the control group showed polymorphisms for 3 genes simultaneously; this reinforces the theory that more the polymorphisms (p53, GSTM1, GSTT1, PROGINS, ER $\beta$ and CYP1A1) a patient carries, greater the risk of developing endometriosis as well as greater the risk of developing severe forms of the disease.

\section{Conflicts of interest}

The authors declare no conflict of interest.

\section{ACKNOWLEDGMENTS}

We would like to thank all who helped to make this study possible including all laboratory staff. 


\section{REFERENCES}

Arndt V, Stürmer T, Stegmaier C, Ziegler H, et al. (2002). Patient delay and stage of diagnosis among breast cancer patients in Germany -- a population based study. Br. J. Cancer 86: 1034-1040. http://dx.doi.org/10.1038/sj.bjc.6600209

Arvanitis DA, Goumenou AG, Matalliotakis IM, Koumantakis EE, et al. (2001). Low-penetrance genes are associated with increased susceptibility to endometriosis. Fertil. Steril. 76: 1202-1206. http://dx.doi.org/10.1016/S0015$\underline{0282(01) 02865-5}$

Arvanitis DA, Koumantakis GE, Goumenou AG, Matalliotakis IM, et al. (2003). CYP1A1, CYP19, and GSTM1 polymorphisms increase the risk of endometriosis. Fertil. Steril. 79 (Suppl 1): 702-709. http://dx.doi.org/10.1016/ $\underline{\mathrm{S} 0015-0282(02) 04817-3}$

Babu KA, Reddy NG, Deendayal M, Kennedy S, et al. (2005). GSTM1, GSTT1 and CYP1A1 detoxification gene polymorphisms and their relationship with advanced stages of endometriosis in South Indian women. Pharmacogenet. Genomics 15: 167-172. http://dx.doi.org/10.1097/01213011-200503000-00005

Baranova H, Bothorishvilli R, Canis M, Albuisson E, et al. (1997). Glutathione S-transferase M1 gene polymorphism and susceptibility to endometriosis in a French population. Mol. Hum. Reprod. 3: 775-780. http://dx.doi.org/10.1093/ $\underline{\text { molehr/3.9.775 }}$

Baxter SW, Thomas EJ and Campbell IG (2001). GSTM1 null polymorphism and susceptibility to endometriosis and ovarian cancer. Carcinogenesis 22: 63-65. http://dx.doi.org/10.1093/carcin/22.1.63

Bischoff F and Simpson JL (2004). Genetics of endometriosis: heritability and candidate genes. Best Pract. Res. Clin. Obstet. Gynaecol. 18: 219-232. http://dx.doi.org/10.1016/j.bpobgyn.2004.01.004

Bocker J, Tadmor OP, Gal M, Diamant YZ, et al. (1994). The prevalence of adenomyosis and endometriosis in an ultra-religious Jewish population. Asia Oceania J. Obstet. Gynaecol. 20: 125-129. http://dx.doi. org/10.1111/j.1447-0756.1994.tb00437.x

Bonfitto VL and de Angelo Andrade LA (2003). p53, estrogen and progesterone receptors in diagnostic curettage for endometrial adenocarcinoma and their correlation with morphological data and disease stage at hysterectomy. Sao Paulo Med. J. 121: 163-166. http://dx.doi.org/10.1590/S1516-31802003000400005

Camargo-Kosugi CM, D'Amora P, Kleine JP, Carvalho CV, et al. (2014). TP53 gene polymorphisms at codons 11, 72, and 248 and association with endometriosis in a Brazilian population. Genet. Mol. Res. 13: 6503-6511. http://dx.doi. org/10.4238/2014.August.26.1

Casado-Vela J, Rodriguez-Suarez E, Iloro I, Ametzazurra A, et al. (2009). Comprehensive proteomic analysis of human endometrial fluid aspirate. J. Proteome Res. 8: 4622-4632. http://dx.doi.org/10.1021/pr9004426

Cauchi S, Stücker I, Cénée S, Kremers P, et al. (2003). Structure and polymorphisms of human aryl hydrocarbon receptor repressor (AhRR) gene in a French population: relationship with CYP1A1 inducibility and lung cancer. Pharmacogenetics 13: 339-347. http://dx.doi.org/10.1097/00008571-200306000-00005

Costa IR, Silva RC, Frare AB, Silva CT, et al. (2011). Polymorphism of the progesterone receptor gene associated with endometriosis in patients from Goiás, Brazil. Genet. Mol. Res. 10: 1364-1370. http://dx.doi.org/10.4238/vol10-3gmr913

Frare AB, Barbosa AM, Costa IR, Souza SR, et al. (2013). GSTM1 and GSTT1 polymorphisms in endometriosis in women from Goiás, Brazil. Genet. Mol. Res. 12: 2764-2770. http://dx.doi.org/10.4238/2013.August.2.1

Gao X, Outley J, Botteman M, Spalding J, et al. (2006). Economic burden of endometriosis. Fertil. Steril. 86: 1561-1572. http://dx.doi.org/10.1016/j.fertnstert.2006.06.015

Hadfield RM, Manek S, Weeks DE, Mardon HJ, et al.; OXEGENE Collaborative Group (2001). Linkage and association studies of the relationship between endometriosis and genes encoding the detoxification enzymes GSTM1, GSTT1 and CYP1A1. Mol. Hum. Reprod. 7: 1073-1078. http://dx.doi.org/10.1093/molehr/7.11.1073

Kawajiri K, Nakachi K, Imai K, Watanabe J, et al. (1993). Germ line polymorphisms of p53 and CYP1A1 genes involved in human lung cancer. Carcinogenesis 14: 1085-1089. http://dx.doi.org/10.1093/carcin/14.6.1085

Koninckx PR, Oosterlynck D, D'Hooghe T and Meuleman C (1994). Deeply infiltrating endometriosis is a disease whereas mild endometriosis could be considered a non-disease. Ann. N. Y. Acad. Sci. 734: 333-341. http://dx.doi. org/10.1111/j.1749-6632.1994.tb21763.x

Kyama CM, Mihalyi A, Gevaert O, Waelkens E, et al. (2011). Evaluation of endometrial biomarkers for semi-invasive diagnosis of endometriosis. Fertil. Steril. 95: 1338-1343.e1. http://dx.doi.org/10.1016/j.fertnstert.2010.06.084

Lao X, Chen Z and Qin A (2016). p53 Arg72Pro polymorphism confers the susceptibility to endometriosis among Asian and Caucasian populations. Arch. Gynecol. Obstet. 293: 1023-1031. http://dx.doi.org/10.1007/s00404-015-3923-7

Maeda K, Tsuda H, Hashiguchi Y, Yamamoto K, et al. (2002). Relationship between p53 pathway and estrogen receptor status in endometrioid-type endometrial cancer. Hum. Pathol. 33: 386-391. http://dx.doi.org/10.1053/ $\underline{\text { hupa.2002.124720 }}$ 
Martini FH, Nath JL and Bartholomew EF (2012). Fundamentals of anatomy and physiology: the reproductive system. $9^{\text {th }}$ edn. Pearson Benjamin Cummings, San Francisco, CA, 1031-1075.

Nakata LC, Bertollo EMC, Dos Santos I, Oliani AH, et al. (2004). Pavarino; Biomarcadores de Susceptibilidade à Endometriosis. Rev. Bras. Ginecol. Obstet. 26: 299-304. http://dx.doi.org/10.1590/S0100-72032004000400006

Nnoaham KE, Hummelshoj L, Webster P, d'Hooghe T, et al.; World Endometriosis Research Foundation Global Study of Women's Health consortium (2011). Impact of endometriosis on quality of life and work productivity: a multicenter study across ten countries. Fertil. Steril. 96: 366-373.e8. http://dx.doi.org/10.1016/j.fertnstert.2011.05.090

Nothnick WB (2001). Treating endometriosis as an autoimmune disease. Fertil. Steril. 76: 223-231. http://dx.doi. org/10.1016/S0015-0282(01)01878-7

Ortega MM, Honma HN, Zambon L, Lorand-Metze I, et al. (2007). GSTM1 and codon 72 P53 polymorphism in multiple myeloma. Ann. Hematol. 86: 815-819. http://dx.doi.org/10.1007/s00277-007-0347-x

Paul Dmowski W and Braun DP (2004). Immunology of endometriosis. Best Pract. Res. Clin. Obstet. Gynaecol. 18: $245-$ 263. http://dx.doi.org/10.1016/j.bpobgyn.2004.02.001

Quiñones LA, Irarrázabal CE, Rojas CR, Orellana CE, et al. (2006). Joint effect among p53, CYP1A1, GSTM1 polymorphism combinations and smoking on prostate cancer risk: an exploratory genotype-environment interaction study. Asian J. Androl. 8: 349-355. http://dx.doi.org/10.1111/j.1745-7262.2006.00135.x

Ribeiro Júnior CL, Arruda JT, Silva CT and Moura KK (2009). Analysis of p53 codon 72 gene polymorphism in Brazilian patients with endometriosis. Genet. Mol. Res. 8: 494-499. http://dx.doi.org/10.4238/vol8-2gmr593

Ricci MS, Toscano DG, Mattingly CJ and Toscano WA, Jr. (1999). Estrogen receptor reduces CYP1A1 induction in cultured human endometrial cells. J. Biol. Chem. 274: 3430-3438. http://dx.doi.org/10.1074/jbc.274.6.3430

Rogers PA, D'Hooghe TM, Fazleabas A, Gargett CE, et al. (2009). Priorities for endometriosis research: recommendations from an international consensus workshop. Reprod. Sci. 16: 335-346. http://dx.doi.org/10.1177/1933719108330568

Romano A, Delvoux B, Fischer DC and Groothuis P (2007). The PROGINS polymorphism of the human progesterone receptor diminishes the response to progesterone. J. Mol. Endocrinol. 38: 331-350. http://dx.doi.org/10.1677/ ime. 1.02170

Sampson JA (1927). Peritoneal endometriosis due to the menstrual dissemination of endometrial tissue into the peritonial cavity. Am. J. Obstet. Gynecol. 14: 422-469. http://dx.doi.org/10.1016/S0002-9378(15)30003-X

Sangihaghpeykar H and Poindexter AN, 3rd (1995). Epidemiology of endometriosis among parous women. Obstet. Gynecol. 85: 983-992. http://dx.doi.org/10.1016/0029-7844(95)00074-2

Silva RC, Costa IR, Bordin BM, Silva CTX, et al. (2011). RsaI polymorphism of the ER $\beta$ gene in women with endometriosis. Genet. Mol. Res. 10: 465-470. http://dx.doi.org/10.4238/vol10-1gmr940

Soto-Quintana O, Cabrera-Galeana P, Téllez-Trevilla G, Barrera-Franco JL, et al. (2011). Relationship of polymorphisms of glutathione S-transferase GSTT1 and GSTM1 with the response to chemotherapy in Mexican women with advanced breast cancer. J. Cancer Ther. 2: 354-361. http://dx.doi.org/10.4236/jct.2011.23048

Tsuchiya M, Katoh T, Motoyama H, Sasaki H, et al. (2005). Analysis of the AhR, ARNT, and AhRR gene polymorphisms: genetic contribution to endometriosis susceptibility and severity. Fertil. Steril. 84: 454-458. http://dx.doi. org/10.1016/j.fertnstert.2005.01.130

Wang YC, Chen CY, Wang HJ, Chen SK, et al. (1999). Influence of polymorphism at p53, CYP1A1 and GSTM1 loci on p53 mutation and association of p53 mutation with prognosis in lung cancer. Zhonghua Yi Xue Za Zhi 62: 402-410.

Yang X, Long S, Deng J, Deng T, et al. (2013). Glutathione S-transferase polymorphisms (GSTM1, GSTT1 and GSTP1) and their susceptibility to renal cell carcinoma: an evidence-based meta-analysis. PLoS One 8: e63827. http://dx.doi. org/10.1371/journal.pone. 0063827 